\title{
CRONICA DE LAS II JORNADAS DE ESTUDIO SOBRE PRESUPUESTO Y CONTABILIDAD DE LAS ENTIDADES LOCALES
}

\author{
por \\ Valentín Pérez Martínez \\ Colaborador del Departamento de Derecho Administrativo \\ de la Facultad de Derecho de la Universidad de Salamanca
}

Durante los días 22 a 24 de octubre de 1986 han tenido lugar las II Jornadas de Estudio sobre Presupuestos y Contabilidad de las" Entidades Locales, convocadas por el Instituto de Estudios de Administración Local y organizadas por la Delegación Interprovincial del Instituto de Estudios de la Administración Local en Sevilla, con la colaboración del Excelentísimo Ayuntamiento y Diputación Provincial de Sevilla.

Las ponencias fueron presentadas por profesores, interventores y economistas, teniendo lugar, asimismo, la exposición de comunicaciones, tras las cuales se suscita el coloquio en torno a aquellos aspectos de más relevancia para las Corporaciones locales que habían sido objeto de estudio por los conferenciantes.

Las expresadas Jornadas se desarrollaron en base a las siguientes sesiones de estudios:

\section{FUENTES DE FINANCIACION DE LAS ENTIDADES LOCALES Y EQUILIBRIO PRESUPUESTARIO}

\section{Ponente: D. JosÉ VALLÉs FERRER}

Puso de relieve la escasa incidencia de los ingresos patrimoniales o de derecho privado, alegando la poca preocupación por los 
mismos, debido fundamentalmente a falta de servicios de Patrimonio actualizados que impide el que se conozca la cuantía, composición y movilidad del patrimonio municipal. La cuantía media de estos ingresos no llega al 50 por 100, con respecto a otros países europeos.

En materia de tributos manifestó que conforman el eje sustancial de los recursos locales. El actual es un sistema fiscal anacrónico que no contribuye a la modernidad, racionalidad y justicia tributarias. Muchas de estas figuras fiscales podrían desaparecer porque cuesta más el recaudarlas que lo que se obtiene por ellas. Sin embargo, los ingresos de derecho público son el eje fundamental de los recursos locales.

En cuanto al Fondo Nacional de Cooperación Municipal constituye una participación no homologable con los sistemas europeos.

Hay que añadir a las fuentes de financiación mencionadas, que el conferenciante califica de internas, aquellas otras que denomina como externas: así, la apelación al crédito, al sistema financiero, que conforman una fuente de financiación muy importante. Sobre un índice 100 de todas las fuentes de financiación en 1978 hasta 1985, tanto a nivel de capitales de Provincia como de Municipios en general, el crecimiento de estos ingresos es importante, presentando enormes tasas de crecimiento, tanto en términos cualitativos como cuantitativos.

Esto va a ser más importante en el futuro y hay que tener en cuenta los objetivos políticos, económicos, regionales y nacionales que los condicionen.

Las subvenciones tienen escasa importancia y presentan porcentajes de crecimiento muy pequeños.

Se pregunta el ponente sobre cuál puede ser el punto de partida en materia de equilibrio presupuestario. En este sentido, manifiesta que el Presupuesto tiene que ser equilibrado, tanto en su formación como en su ejecución. No se puede renunciar a la unidad presupuestaria ni al equilibrio presupuestario, pero tampoco mantener la coordinación de los agentes del Presupuesto ni a una mejor asignación de los recursos, ni se renuncia tampoco a la cobertura legal de las necesidades locales.

El conferenciante propuso la remodelación del marco de financiación de las Corporaciones locales en el siguiente sentido:

1) Fuentes de financiación internas (de Derecho privado): modernizar los servicios de Patrimonio, es decir, hay que tratar 
el patrimonio cualitativa y cuantitativamente de otra manera. Hay que conocer mejor y valorar mejor el patrimonio, enajenando cuando convenga y ajustando la propiedad inmobiliaria municipal a lo que se debe. De otro lado, hay que llevar a cabo una política de actualización de rentas de otros valores.

2) Fuentes de Derecho público: partiendo del anacronismo de muchas figuras fiscales, la financiación interna podría quedar asegurada por los dos últimos borradores - de los cuatro existentesde la Ley de Haciendas locales, según la siguiente propuesta:

a) Mantenimiento del impuesto sobre el patrimonio de bienes inmuebles, absorbiendo los tributos locales de carácter real.

Se señala la no conveniencia de eliminar el impuesto de Plus Valía, por lo que el citado impuesto debería englobar sólo a las Contribuciones Territoriales Rústica y Pecuaria y Urbana. A juicio del ponente, la conveniencia de mantener el impuesto de Plus Valía se debe a razones de justicia económica y de buen funcionamiento del mismo.

b) Impuesto sobre la actividad económica, que englobaría las Licencias Fiscales, el impuesto de Radicación y las tasas por licencia de apertura.

Otras figuras impositivas serían las relativas a la imposición indirecta:

a) Impuesto sobre la Circulación, que sería mejor se traduzca en una participación en el porcentaje de la venta de la gasolina.

b) Impuesto municipal sobre construcciones, instalaciones $\mathbf{y}$ obras, que englobaría las tasas por licencias de obras, ya que las de apertura se entiende subsumida en el impuesto sobre la actividad económica.

c) Hay que reivindicar una participación en el IVA porque permitiría cerrar el cuadro de las figuras locales para mantener el equilibrio presupuestario.

3) El Fondo Nacional de Cooperación Municipal: Los criterios de participación de los Municipios son mejores que los que rigen la participación de las Comunidades Autónomas en el Fondo de Compensación Interterritorial, aunque sea la mejor forma de obtener este último. Hay que reivindicar frente a la idea de cupo o de tanto alzado en la correspondiente Ley de Presupuestos de cada año, defender la necesidad del porcentaje sobre esa participación, de tal manera que a mayores ingresos corresponda mayor participación y no discutir un tanto alzado como ahora. Sin em- 
bargo, hay que mantener criterios de distribución: población, esfuerzo fiscal y número de aulas de EGB existentes en la actualidad.

Esta fuente de financiación de Derecho público en los ingresos del Estado (Capítulos I y II) es necesario complementarla con otros ingresos de Derecho público.

4) El Gobierno o, más bien, las administraciones públicas -Gobierno y Comunidades Autónomas - tienen que hacer un esfuerzo para que los Municipios que tienen que prestar un servicio de transporte público urbano, que ha sido y es deficitario, puedan financiar el mismo y si se quiere equilibrar el Presupuesto hay que arbitrar medios, que son más ingresos de derecho público y en este sentido hay que transformar el subfondo del transporte existente dentro del Fondo Nacional de Cooperación Municipal, que lo financia con dos o tres años (dos a nivel presupuestario más uno a nivel de tesorería) de retraso.

La propuesta sería:

a) Que se financie la totalidad del déficit.

b) Que se financie año a año.

c) Que lo financie ex ante y revierta la cobertura pagando el Gobierno los costes de financiación.

Respecto a los ingresos de derecho privado se planteó el acudir al sistema financiero público y privado y es necesario acudir a los programas de inversiones públicas. Es importante el nivel de endeudamiento alcanzado, especialmente si se compara con los niveles europeos.

Hay que moderar la apelación al crédito, pero no sustituirla, sin perder de vista que ha de ser para inversiones públicas y que debe ser coordinada con los Gobiernos de la Nación y de la Región y que su finalidad ha de ser la mejora de las infraestructuras.

El ponente se manifiesta disconforme con el tratamiento legal de la carga fiscal, debiendo distinguirse un doble tratamiento de la carga fiscal, distinguiendo entre carga financiera directa e indirecta, separando los respectivos topes. En estos momentos el tratamiento que se hace de la carga fiscal no es homologable ni en la cuantía ni en la fórmula de cálculo a la Comunidad Económica Europea.

5) Para garantizar el equilibrio presupuestario no basta lo anterior, ya que respecto a los equilibrios anteriores correspondientes a los ejercicios comprendidos entre 1982-1983 y 1986 hay 
que defender el saneamiento del déficit de estos años. En este sentido afirma que se ha saneado buena parte de las estructuras locales y que la Ley de Saneamiento ha servido en gran medida para sanear el déficit estructural, pero hay que culminar esta labor, fundamentalmente en la vertiente del transporte, por lo que o se hace «borrón y cuenta nueva» o hay que hacer otra Ley de Saneamiento para soltar lastre de carga financiera.

En cuanto al gasto público afirmó:

1) Hay que separar los servicios públicos obligatorios y voluntarios, los servicios públicos urbanos, locales, de los transferidos por otras administraciones públicas y que, sin embargo, no se han transferido los medios de financiación y que influyen en el problema del desequilibrio presupuestario de las Corporaciones locales.

2) El Estado y las Comunidades Autónomas tienen que asumir directamente ciertas cargas municipales en los ámbitos educativo, sanitario, limpieza viaria, etc., o bien tienen que transferir recursos.

3) Hay que moderar las posibilidades, la política local en materia de empleo, que se hace en colaboración con las Comunidades Autónomas y el Gobierno de la Nación, porque hipoteca el Presupuesto General (parte del Presupuesto ordinario), impidiendo la formación bruta de capital.

\section{BONIFICACIONES Y EXENCIONES FISCALES EN LA ADMINISTRACION LOCAL}

Ponente: D. Jesús Loscos Puig

Según algunas opiniones doctrinales estos beneficios pueden alcanzar el 50 por 100 de la capacidad tributaria local. Las causas de su existencia obedecen a razones de índole social y económica, así como a la presión de grupos sociales y a la inercia administrativa -(PÉrez De Ayala)-. Según Albiñana, en estudio referido a 1982, hay sectores productivos en los que resultaría difícilmente justificable.

El tratamiento dado en la legislación tiene una enorme dimensión e importancia. Se recogen ya en 1927 en un informe sobre 
auxilios a la industria nacional. En la legislación vigente se alude a las bonificaciones y exenciones tributarias, la Ley General Tributaria (art. 41.1), la Ley General Presupuestaria (art. 58.3) y la propia Constitución, que en su artículo 134.2 establece para la Administración del Estado la obligatoriedad de cuantificar los beneficios fiscales y acompañarlos a los Presupuestos Generales del Estado, lo que se viene haciendo desde 1979 con la referencia a un presupuesto de gastos fiscales.

Respecto al Plan General de Contabilidad Pública -Orden Ministerial de 14 de noviembre de 1981 - en su plan de cuentas se refiere en el grupo 0 al control presupuestario y en el 02 al control de los gastos fiscales.

El ponente hizo referencia a los estudios relativos a la evolución de los presupuestos de gastos fiscales, cifrados en 1961 en 424.000 millones de pesetas, lo que suponía un 23,5 por 100 del Presupuesto de ingresos, mientras que en 1982 ascendió a 555.000, en 1983 a 691.000 , en 1984 a 820.000 y en 1985 ha ascendido a 907.000 , alcanzando ya a un 27,2 por 100 del Presupuesto.

En 1967, y referidos al total de derechos contraídos y liquidados, se estimaba que suponían un 47 por 100 de la capacidad tributaria local.

Es difícil encontrar una justificación teórica, hay autores, como SAINZ DE BUJANDA, que se refieren a la vulneración del principio de capacidad económica o contributiva, consagrado en el artículo 31.1 de la Constitución y en el artículo 3. de la Ley General Tributaria.

Respecto a los beneficios fiscales locales se interfieren dos bloques normativos y el problema debe resolverse teniendo en cuenta principios como el de la autonomía tributaria local y los de legalidad y jerarquía normativas.

Es necesario estudiar en el campo local el coste fiscal de los beneficios tributarios. Hasta ahora sólo se han hecho dos estudios limitados, en cuanto su alcance, en los Ayuntamientos de La Coruña y Salamanca, trabajos humildes en cuanto que se refieren a la cuantificación de las exenciones respecto de las Viviendas de Protección Oficial. A este respecto, según el estudio de La Coruña (1979) alcanzaban un 52,26 por 100 de la capacidad tributaria local y el de Salamanca (1983) los estimaba en un 68 por 100.

Se refiere el ponente, a continuación, a la incidencia de los principios generales antes citados: 
a) Principio de autonomía financiera y tributaria local.

La Constitución española establece en su artículo 137 el principio político de la autonomía y el Tribunal Constitucional, en sentencias de 2 de febrero y 13 de julio de 1981, precisó el alcance del principio de autonomía local, haciendo referencia a un poder limitado frente al principio de soberanía.

Sin autonomía financiera no puede hablarse de autonomía político-administrativa, que se debe traducir, tanto en la vertiente de ingreso (poder tributario) como del gasto (poder determinar los objetivos dentro del marco diseñado por el legislador).

A partir de la Constitución se produce un cambio sustancial: el liquidador ordinario queda obligado a arbitrar normas que posibiliten un sistema tributario propio (art. 142).

En los artículos 106.1 y 5.E) de la Ley 7/1985 aparece configurado el marco normativo y las Corporaciones locales tienen autonomía para regular en Ordenanzas todos los elementos configuradores del tributo $\mathrm{y}$, por tanto, también los beneficios tributarios.

Teniendo en cuenta que la disposición final séptima, 2, del Real Decreto legislativo 781/1986 establece que la regulación contenida en el Título VIII constituye la legislación estatal a que se refiere el artículo 5.-E) de la Ley $7 / 1985$, habrá que considerar que se trata de un contenido normativo transitorio.

El Tribunal Constitucional mantiene una doctrina restrictiva: las Corporaciones locales no gozan propiamente de autonomía tributaria, sino de suficiencia de recursos. Idéntica doctrina postula el Tribunal Supremo.

El artículo 721 de la Ley de Régimen Local de 1955 suponía una derogación de normas del Ordenamiento Tributario, pero tuvo un éxito reducido respecto a la necesidad de que el Estado compensase a las Corporaciones locales el importe de las exenciones, ya que el propio legislador dejó a salvo la posibilidad de que no tuviere eficacia el precepto.

La jurisprudencia ha sido restrictiva al interpretar el artículo 721, por lo que su eficacia ha sido nula.

b) Principio de legalidad tributaria.

El marco normativo está establecido en los artículos 31 y 133 de la Constitución, 2.10 y 11 de la Ley General Tributaria, 26 y 27 de la Ley de Régimen Jurídico de la Administración del Estado y 30.2 de la Ley General Presupuestaria. Pero sólo se garantiza la exigencia de Ley para la creación del tributo y para los elementos 
fundamentales, pero no para las modificaciones o anulaciones, como son las exenciones.

Varias Sentencias del Tribunal Constitucional (31 de mayo de 1982, 4 de febrero de $1983 \ldots$ ) hacen esta interpretación que puede verse explícitamente en el Fundamento Jurídico $60^{\circ}$ de la Sentencia de 4 de febrero de 1983. La doctrina es crítica con esta interpretación al opinar que se introduce un principio de deslegalización y porque pugna con la exigencia del artículo 10 de la Ley General Tributaria, de que exista una ley formal para su regulación.

Se ha intentado poner fin a esta situación mediante normas de carácter local:

a) Artículo 719 de la Ley de Régimen Local de 1955: principio de legalidad tributaria, pero los Tribunales le restaron validez al entender que debía haberse establecido una tabla derogatoria.

b) Artículo 10 de la Ley 85/1962: facultaba al Gobierno para regular las exenciones y bonificaciones. Puede consultarse al respecto la Sentencia de la AT de Sevilla de 12 de febrero de 1965.

c) Disposición final tercera de la Ley 41/1975: derogaba las normas y daba un plazo de seis meses para adaptar las que estuviesen contenidas en disposiciones que no fueran de carácter local.

d) Disposición transitoria segunda del Real Decreto 3250/1976: continuaban en vigor las exenciones y bonificaciones comprendidas en normas con rango de ley que no fuesen de régimen local, en tanto no se cumpliere la previsión anterior.

e) Real Decreto legislativo 781/1986: fuera de los preceptos recogidos en el mismo, los demás hay que entenderlos contrarios al principio de autonomía y no tienen validez. No obstante, los beneficios contemplados en normas con rango de ley que no son de régimen local, a pesar de entenderlas derogadas, es previsible que la doctrina que sienten los Tribunales no vaya a ser la misma, toda vez que hasta el momento ha sido enormemente restrictiva.

\section{ASPECTOS JURIDICOS DE LAS HACIENDAS LOCALES}

Ponente: D. JosÉ ORTIZ DIAZ

Hay aspectos jurídicos «a caballo» entre lo administrativo y lo fiscal. La Ley 7/1985 y el Real Decreto legislativo 781/1986 ponen fin a una situación de inestabilidad jurídica preexistente. 
El proceso de pérdida de influencia del principio de tutela en el ámbito local ha sido gradual y progresivo hasta su supresión. Los Estatutos de Autonomía de Cataluña, Galicia y Andalucía mantienen la «tutela financiera» de las Comunidades Autónomas sobre las entidades locales, pero no pueden incluir los controles jurídico-administrativos de la tutela anterior, sino que se refieren a la contribución de las Comunidades Autónomas a aumentar la capacidad financiera de las Corporaciones locales; por ejemplo, a través de las operaciones de crédito.

El principio de autonomía para las Corporaciones locales y las Comunidades Autónomas viene recogido en los artículos 137 y 156 de la Constitución.

El ponente opina que hay que ir hacia una hacienda de colaboración, de integración entre las diferentes administraciones públicas.

La regulación de las Haciendas locales en la Ley $7 / 1985$, no es muy extensa porque no se regulan en la misma los impuestos locales; por el contrario, el contenido del Texto Refundido a este respecto es muy extenso.

¿Cuál es el bloque normativo de las Haciendas locales? Está previsto en el artículo 105 de la Ley 7/1985 en concordancia con su artículo 5.-E), estableciéndose tres niveles normativos. El artículo 105 casi reproduce el artículo 142 de la Constitución, que carece de precedentes en la historia constitucional, ya que supone la constitucionalización de los principios que rigen las Haciendas locales. No obstante, el artículo 142 no formula un poder tributario previo, sino que lo que proclama es un principio de suficiencia de medios de las Corporaciones locales. Este es un concepto ambiguo o lo que se conoce como conceptos jurídicos indeterminados y que, por consiguiente, hay que integrar.

Los preceptos citados establecen un sistema mixto de financiación con complejidad de formas tributarias: tributos propios y participaciones que están amparadas constitucionalmente. Queda abierta la posibilidad de que por ley se prevean otros recursos, quizás pensando en los recargos, aunque no se aluda expresamente a ellos en la Constitución como se hace en el caso de las Comunidades Autónomas.

El artículo 106 de la Ley 7/1985 hace una formulación expresa de la potestad autonómica de las Corporaciones locales. Hay que tener en cuenta la clasificación que de las Entidades locales hace 
esta Ley, ya que en su artículo 106.3 dispone que las competencias en materia de gestión, recaudación e inspección pueden ser delegadas, pero no las potestades tributarias. A este respecto hay que tener en cuenta que los consorcios no son Entidades locales, al menos no se dice. El artículo 110 del Texto Refundido habla de que las Entidades locales pueden constituir consorcios, por lo que tienen una configuración jurídica nueva, al permitir que formen parte de las mismas entidades privadas sin ánimo de lucro, pero sigue siendo una forma asociativa entre Entidades públicas de distinto nivel, entre entidades de diferente orden al local y éstas.

La Constitución reserva la potestad tributaria originaria al Estado, las demás Administraciones la tienen derivada, aunque esto sería discutible en el caso de las Comunidades Autónomas. ¿El poder originario del Estado significa la creación ex novo del impuesto o algo más? Se refiere a la creación del tributo y a la fijación de los elementos esenciales del mismo, pero no comprende el desarrollo de todo el proceso impositivo hasta el final, ya que para eso está la potestad reglamentaria de las Corporaciones locales. Por otra parte, ¿qué alcance tiene la potestad derivada? El artículo 133 de la Constitución establece que corresponde al Estado la potestad de establecer y exigir tributos, pero esto también lo dice la legislación de régimen local para las Corporaciones locales, por lo que hay que establecer, a juicio del ponente, la distinción entre impuestos locales obligatorios y potestativos. Para todos ellos tiene potestad el Estado y dentro de la autonomía de las Corporaciones locales entrarían los impuestos potestativos; interpretación en línea con lo dispuesto en el artículo $5 .^{\circ}$ de la Ley General Tributaria, según el cual, las Corporaciones locales pueden establecer tributos cuando sean potestativos.

Respecto al ámbito de aplicación territorial de las Ordenanzas Fiscales, los artículos 21 de la Ley General Tributaria y 107 de la Ley 7/1985 fijan el principio de residencia efectiva de las personas naturales y el domicilio social para las jurídicas. Pero el artículo 106 de la Ley 7/1985 añade un precepto nuevo como es el que las Corporaciones locales pueden dictar disposiciones interpretativas o aclaratorias, que para ser efectivas deben expresarse en el Tablón de anuncios del Ayuntamiento y publicarse en el Boletín Oficial, sin que sea preciso seguir el procedimiento para la elaboración y aprobación de las Ordenanzas Fiscales. 
Se refirió a continuación el ponente a las reclamaciones y recursos, manteniendo que la fase de reclamaciones se produce ante la Corporación después de la aprobación inicial, mientras que la fase de recursos se inicia después de la aprobación definitiva. Parece que, según el artículo 113 de la Ley $7 / 1985$, un acto sobre el que no se hubiere efectuado reclamación no podría interponerse el recurso contencioso-administrativo, lo que constituye una especie de "seguro contra la ilegalidad", rozando una posible inconstitucionalidad. Pero el Texto Refundido ha salvado este obstáculo diciendo que son recurribles los acuerdos definitivos, rectificación que, sin embargo, sólo opera respecto de las Ordenanzas, pero no en cuanto a los Presupuestos.

Por último, hizo una breve referencia a la desaparición de las reclamaciones económico-administrativas en el ámbito local.

ASPECTOS PUNTUALES DE LA LEY GENERAL PRESUPUESTARIA Y DE LAS LEYES DE PRESUPUESTOS DE INTERES A LAS CORPORACIONES LOCALES

Ponente: D. Eduardo Olavarría Téllez

Partiendo de que la Ley General Presupuestaria de 4 de noviembre de 1977 es supletoria en materia de Haciendas locales, trata el conferenciante de ver las posibilidades que la misma ofrece para aplicarla a las Corporaciones locales como derecho supletorio.

La reforma se inició en 1979 con dos aspectos diferenciados: político y económico. En el aspecto político, trata de hacer realidad el principio de autonomía en materia de presupuestos locales, quedando cerrado el proceso con la Ley 40/1981, ya que la Ley $7 / 1985$ y el Real Decreto legislativo $781 / 1986$ no alteran en nada la situación. En cuanto al aspecto económico mantiene que la reforma técnica de los presupuestos locales es más compleja, ya que los avances en el campo presupuestario han sido muy profundos y ha sido objeto de múltiples disposiciones legales, recogiéndose expresamente en las disposiciones citadas en último lugar, refundiendo el Real Decreto legislativo 781/1986 las dis- 
posiciones legales vigentes, al mismo tiempo que regulariza, aclara y armoniza dichas normas.

Las disposiciones refundidas, según la disposición transitoria primera de la Ley de Bases, constituyen la legislación estatal aplicable en los términos expuestos en su artículo $5 .^{\circ}$ Por lo tanto, la Ley General Presupuestaria es supletoria de esta legislación, aunque en muchos casos no es supletoria, sino que sirve para aportar criterios para su interpretación.

La vigencia del principio presupuestario de unidad plantea dudas. En la Ley de Régimen Local de 1955 no existe, ya que regula junto al presupuesto ordinario los presupuestos especiales y extraordinarios. Será la Ley 41/1975 la que establezca el Presupuesto único, lo que constituye el punto de partida, refiriéndose el Real Decreto-ley 11/1979 a un Presupuesto General consolidado, pero en el Real Decreto-ley 3/1981 se alude a un Presupuesto de inversiones junto al Presupuesto Ordinario. La Ley 40/1981 habla ya de Presupuesto Ordinario único, aunque admite también el de inversiones, si así se adopta por las Corporaciones locales. Por último, la Ley de Bases se refiere al Presupuesto único y el Texto Refundido a un Presupuesto General.

El Real Decreto-ley 11/1979 no resulta muy afortunado al añadir la expresión "consolidado» al Presupuesto General, porque exigía la existencia de elementos que se consolidan. En cambio, en el proyecto del Real Decreto-ley 3/1981 se preveía la existencia de un Presupuesto único pero se estimó precipitado y no tendrá lugar su plasmación legal hasta la Ley de Bases, que en su artículo 85 establece las diferentes formas de gestión de los servicios públicos.

El artículo 443 del Real Decreto legislativo 781/1986 habla ya de Presupuesto General, lo que es correcto, siendo el término empleado por la Ley General Presupuestaria, pero no lleva al extremo el principio de unidad presupuestaria porque cada ente dependiente ha de formar su propio presupuesto y ejecutarlo igualmente, por lo que la integración de estos presupuestos en el General forma un todo, pero es una unidad presupuestaria relativa, ya que la unidad absoluta exigiría que todos los ingresos y gastos estuvieren en un solo Presupuesto, conllevando al mismo tiempo el principio de unidad absoluta de caja.

El artículo 50 de la LGP sólo considera integrantes de los Presupuestos Generales del Estado, el propio Estado y los organismos 
autónomos de carácter administrativo, excluyendo los correspondientes a los organismos autónomos que no tienen este carácter y a los de las sociedades estatales.

Hay que tener en cuenta que las modificaciones de la Ley General Presupuestaria son producto de la propia Constitución y, concretamente, de lo establecido en su artículo 134.2.

El sentido de un Presupuesto General integrado es suponer la existencia de presupuestos de los diferentes entes con personalidad juridica propia. Se pregunta el ponente cómo han de formularse estos presupuestos y a este respecto la Ley General Tributaria ofrece distinto tratamiento, puesto que los organismos autónomos administrativos se rigen por las normas de los Presupuestos Generales del Estado, mientras que los demás forman un Presupuesto de explotación y capital y las sociedades estatales un programa de inversiones.

El Estado introduce normas sobre presupuestos a través de una Orden de 21 de abril de 1986, que introduce modificaciones válidas para el Estado y hay que tener en cuenta que, conforme al artículo 52.3 de la Ley General Presupuestaria, la estructura presupuestaria de las Corporaciones locales se adaptará a la del Estado. El Real Decreto-ley 11/1979 ya reproducía el artículo, pero la adaptación —decía- se realizará de forma gradual, pero no fue así, porque ya estaba hecha: La Orden de 14 de noviembre de 1979 estableció la estructura presupuestaria de las Corporaciones locales, que continúa en vigor, aunque se han dado cambios en los estados de ingresos y gastos, tales como los de conceptos tributarios o conceptos salariales de los funcionarios, por ejemplo. Se dejaba fuera a los organismos autónomos, fundaciones, patronatos, sociedades privadas, etc.

Es necesaria una nueva estructura presupuestaria local que se adapte a la del sector público y, a tal efecto, hay que tener en cuenta la regulación de la Ley de Bases de 1985 para realizar esta adaptación. Hay circunstancias que aconsejan un aplazamiento, tales como la prevista reforma de la Ley General Presupuestaria (que parece no va a ser en breve), a cuyo texto refundido se incorporarán las normas interpretativas contenidas en las leyes anuales de Presupuestos Generales del Estado. De otro lado, la futura Ley de Haciendas locales exigirá su acomodación a la Ley General Presupuestaria. 
En la Administración del Estado se da con frecuencia que normas tributarias o o de otra naturaleza se modifican, lo que puede ser un peligro para las Corporaciones locales dadas las dificultades y la inercia con que se ponen en vigor tales reformas en este sector, además de la necesidad de contar con series de datos homogéneos que permitan las estadísticas. De lo dicho se infiere que la estructura presupuestaria ha de tener vocación de permanencia, mientras que la Orden de 21 de abril de 1986, que dicta instrucciones para los Presupuestos Generales del Estado para 1987, dice que es preciso introducir anualmente las modificaciones y así se modifica casi totalmente la estructura de los Presupuestos Generales del Estado, lo que sería muy difícil en la Administración Local. En tanto se produce la aprobación de la citada ley, será aplicable la Orden de 14 de noviembre de 1979, con la excepción de las sociedades a las que se permite aplicar supletoriamente las normas para las sociedades estatales.

El ponente reseñó la importancia de uno de los documentos que se han de unir al Presupuesto General según el artículo 443.2.c) del Texto Refundido, tal es el estado de consolidación del Presupuesto con el de los organismos autónomos y sociedades mercantiles, y que viene a reproducir el artículo 54.3. ${ }^{\mathrm{a}}$ de la Ley General Presupuestaria que se refiere a la cuenta consolidada de los presupuestos. Pues bien, la consolidación debe hacerse a nivel de capítulos y de artículos y aunque el artículo 446.3 lo llama presupuesto consolidado debe entenderse referido a estado consolidado y que equivale a lo que en el Estado se llama cuenta consolidada.

El artículo 444 y siguientes $i$ se refieren al Presupuesto de cada ente que integran el Presupuesto General o a este Presupuesto General? Contestar a esta interrogante es importante, puesto que el artículo $444.4 .^{\circ}$ se refiere a la nivelación presupuestaria (aprobación sin déficit inicial) y si nos referimos a que los presupuestos que se integran tienen déficit, puede conllevar también el del Presupuesto General. La interpretación puede hacerse a la luz del artículo 54.1. ${ }^{a}$ de la Ley General Presupuestaria, que dice que los presupuestos de los organismos autónomos no podrán tener déficit inicial, lo que viene a apoyar la tesis de que cada uno de los presupuestos ha de formarse sin déficit inicial $y$ éste ha de ser el criterio que ha de seguirse respecto del artículo 444 y siguientes del Texto Refundido. 
Otro aspecto importante es el referido al plazo para la aprobación del Presupuesto; a este respecto cabe decir, según el ponente, que no existe plazo para que el Presidente eleve el Presupuesto al Pleno. Si no se aprueba, se prorroga el anterior (el Texto Refundido habla de los créditos iniciales del Presupuesto anterior). El Real Decreto legislativo $781 / 1986$ ha suprimido la expresión «hasta la aprobación del nuevo», que se recogía en la Ley $40 / 1981$, pero sí se puede aprobar, en criterio del ponente, ya que el Texto Refundido establece una derogación y con ello va más allá de lo ordenado por el legislador, con lo que ha habido una extralimitación por parte del Gobierno. La Ley de Bases abre un nuevo plazo, pero no fija término, que, sin embargo, podía haberse añadido por el Texto Refundido. En cualquier caso, la consecuencia a extraer es que cabe la interpretación, apoyada en la Ley General Presupuestaria de que los presupuestos se consideran prorrogados hasta la aprobación y publicación del nuevo.

En cuanto a la ejecución del presupuesto, la unidad presupuestaria viene impuesta en las normas legales, pero este principio no exige que en su ejecución haya unidad -art. 74.2 LGP-, por lo que es cada ente el que ejecuta el Presupuesto y dentro de éstos será el órgano correspondiente el competente para ello.

Por último, se refirió al principio de unidad de caja, aludiendo a la Ley de Finanzas de Cataluña, que en su artículo 58 está copiada respecto a este extremo de la LGP (art. 106), olvidando que esta norma ya estaba obsoleta en algunos aspectos, por lo que la Tesorería de la Generalidad la constituyen todas las de las entidades autónomas y la de la Generalidad.

Cabría establecer una serie de conclusiones respecto de la situación de la legislación local en esta materia tales como que el Texto Refundido suscita dudas sobre estas normas, que algunas se completan con la interpretación analógica y supletoria de la Ley General Presupuestaria, sin olvidar por ello las modificaciones introducidas en la misma y que se exige una nueva redacción de esta Ley. Al mismo tiempo, la futura Ley de Haciendas locales regulará el régimen presupuestario de las Corporaciones locales en coordinación con las del Estado, pero hasta que se produzca su aprobación resultará aplicable a los organismos autónomos comerciales, industriales, etc., y a las sociedades, la estructura aprobada por la Orden de 21 de abril de 1982. 


\section{PRESUPUESTO POR PROGRAMAS Y CONTABILIDAD ANALITICA EN LA ADMINISTRACION LOCAL}

\section{Ponente: D. Juan Ramón Jiménez Pérez}

Se refirió a las técnicas presupuestarias y al control de las Corporaciones locales, así como a los aspectos que motivan la implantación de estos instrumentos. Considera para ello que es necesario marcarse al comienzo de cada ejercicio una serie de objetivos de gestión que son la «antesala» de los programas presupuestarios. Lo importante es determinar para qué se gasta el dinero y a este respecto cabe decir que en la Administración Local existen controles del gasto de carácter de legalidad, pero no de efectividad, de eficacia.

Se está haciendo en la actualidad un presupuesto tradicional que utiliza procedimientos incrementalistas y que no justifican debidamente las partidas como ocurre en la empresa privada. Se está gestionando una contabilidad presupuestaria de ingresos-pagos, pero no de fondos. Hay que hablar en términos de cuentas de explotación y no de déficit o superávit que puede resultar engañoso, porque esa contabilidad no da información de los inventarios.

Es necesario un sistema de control de gestión que posibilite un seguimiento de los objetivos propuestos, por lo que es necesario, asimismo, hablar de presupuesto por programas, pero desde un punto de vista práctico más que teórico.

En el estudio de las fases para la implantación de estos instrumentos de gestión en las Corporaciones locales hay que seguir al Estado respecto de la implantación del Presupuesto por Programas y el Plan General de Contabilidad Pública. En este sentido, el Presupuesto por programas es un presupuesto integrado por objetivos y programas y hay que hacer una distribución más compleja que la distribución en funciones y subfunciones, ya que ahora hay que insertar la fase de presentación con las fases anteriores de planificación y programación de medios y valoración de recursos. Es, pues, un proceso integrado que puede otorgar un carácter gerencial.

Los procesos siguientes son de ejecución, contabilidad y evaluación, que nos permiten conocer el coste de los programas. Aquí 
es necesario, a juicio del ponente, poner de relieve el proceso de implantación del Plan General de Contabilidad Pública.

Hay que tener claro el modelo de planificación a seguir para prever las necesidades que se han de satisfacer, determinando los objetivos, la elección de acciones posibles, etc.

Respecto a los instrumentos que deben tenerse en cuenta, enumera los siguientes:

a) Plan estratégico de actividades y objetivos para el cuatrienio (período de tiempo elegido por coincidir con el de una legislatura). Debe tenerse información suficiente sobre la cantidad, calidad y precio de los servicios que tiene que prestar una Corporación.

b) Revisión anual del Plan estratégico de actividades y objetivos.

c) Desarrollar un plan de gestión anual.

d) Confeccionar un plan integrado de objetivos y programas.

Por lo que se refiere al plan de gestión anual, a juicio del ponente, cada director de área establecerá su propio plan de gestión, que ha de ser preciso y cuantificable al mismo tiempo que valorable. Su aprobación correspondería a la Comisión de Gobierno. Entre la información que debe contener un plan de gestión anual, enumera: La relación de actividades por cada programa de trabajo, la descripción de los objetivos, proceder con detalle a la determinación de los objetivos y las acciones a realizar como partes integrantes de una tarea principal.

En la fase de presupuestación, el carácter limitado de los recursos exige una asignación óptima de los mismos, siendo necesario que la toma de decisiones se haga después de un análisis previo, similar al que se sigue en la empresa privada.

Señaló las modalidades de realización de un Presupuesto por Programas:

$\left.1 .^{2}\right)$ Si se gestiona con Contabilidad Presupuestaria, se podría hacer el Presupuesto por Programas, lo que no se podría hacer sería la fase de seguimiento económico del coste de cada programa.

2. $\left.{ }^{9}\right)$ Si se gestiona con el Plan General de Contabilidad, se utiliza el grupo 9 como instrumento que facilita la información sobre costes y puede hacerse el Presupuesto por Programas, también en la fase de seguimiento.

A continuación procedió al estudio de las diferentes fases que han de seguirse para la implantación de un Presupuesto por Programas. Así, se debe crear una oficina de planificación y control 
de gestión, dotada con personal de la propia Corporación local, que haga un modelo de implantación. Después de referirse a la necesidad de un control y a la envergadura conveniente de la oficina presupuestaria, indicó, en cuanto al organigrama, el criterio de constituir un órgano staff con autonomía total para la implantación de esta técnica, informando al Alcalde de su actividad.

El ponente opina que se deben clasificar las fases del ciclo presupuestario en el aspecto semántico, unificando la terminología a utilizar.

En cuanto al diseño del soporte informativo, distinguió entre el Plan de Gestión y el propio Presupuesto por Programas, debiendo incluirse en el primero una memoria de presentación, la estructura programática, la descripción del contenido y características de cada programa, los objetivos y acciones y los indicadores de eficacia. Para el Presupuesto por Programas señaló, entre otros, la memoria, la distribución del personal laboral, de funciones, etc., entre programas, los instrumentos materiales que utiliza cada programa, los criterios de reparto, etc., etc.

\section{ASPECTOS PUNTUALES DEL CONTROL INTERNO Y EXTERNO DE LAS CORPORACIONES LOCALES}

\section{Primer Ponente: D. Jesús GuijarRo ARrizabalaga}

Comenzó refiriéndose a la distinción de varios aspectos de la fiscalización interna de las Corporaciones locales, así la fiscalización de la recaudación (¿se vigila que las fianzas de los recaudadores estén actualizadas?, ¿se declara y exige el perjuicio de valores), el control de los derechos presupuestados reconocidos y liquidados que pasan de un ejercicio a otro (¿son fiables?, ¿se depuran en resultas?) y el control de los derechos reconocidos ( ¿qué cambio se ha experimentado en el Texto Refundido?, ¿cómo se compagina el reconocimiento extrajudicial de créditos con la carencia de crédito presupuestario suficiente?).

Pasó a continuación a estructurar su intervención en cuatro bloques perfectamente diferenciados:

1. Organos de fiscalización externa:

En cuanto a las competencias que pueden corresponderle a las Comunidades Autónomas, hay que tener en cuenta que el ar- 
tículo 136.1 de la Constitución instituye al Tribunal de Cuentas como supremo órgano fiscalizador de las cuentas y de la gestión económica del Estado y del Sector público. La calificación de supremo al Tribunal de Cuentas parece excluir otros órganos de fiscalización, se instituyan donde se instituyan, pero en realidad cabe su existencia si se da cumplimiento a lo establecido en los artículos 147.2 y 149.3 de la Constitución, así como a los artículos 137 y 140 de la máxima norma de nuestro ordenamiento.

En los Estatutos de Autonomía sólo se alude expresamente a estos órganos en el de Cataluña (art. 42), Galicia (art. 53), Valencia (art. 59) y la Ley de Amejoramiento de Navarra (art. 18). En los dos primeros se señala respecto de la rendición de cuentas, en el de Valencia la fiscalización viene referida al control económico y presupuestario y en el caso navarro al examen y censura de cuentas. En cuanto a la atribución y asunción de competencias, en el País Vasco y Cataluña se hace referencia expresa a las mismas.

El hecho de que existan órganos de control externo no impide la obligación de respetar la autonomía municipal programada por el artículo 137 de la Constitución y así, aunque las Comunidades Autónomas de Cataluña, Galicia y Valencia tienen creados por sus respectivos Estatutos de Autonomía órganos de control externo, que pueden fiscalizar sus órganos internos, esta competencia no se extiende a las Corporaciones locales. Las demás Comunidades Autónomas no pueden crear órganos propios de fiscalización externa. Distinto es el caso de Navarra que cuenta con una Ley Orgánica de 1982, que no es un Estatuto de Autonomía y que de su artículo 18 se infiere una competencia específica de control externo sobre las Corporaciones locales.

Respecto de los órganos de carácter estatal, la regulación del Real Decreto-ley 3/1981 permite pensar en la intromisión del Ministerio de Hacienda (art. 16.3), que podría fiscalizar a las Corporaciones locales, ya que los ingresos procedentes de este Ministerio son importantes y no son finalistas y sirven para satisfacer las necesidades generales de las Corporaciones locales, luego cabría deducir que puede comprobar la totalidad de los gastos locales.

Hay que tener en cuenta que la Sentencia del Tribunal Constitucional de 2 de febrero de 1981 declaró inconstitucionales los artículos que contenían controles por el Ejecutivo sobre las Corporaciones locales, pero el Real Decreto-ley que examina se convirtió en Ley, por lo que continuará la amenaza, si bien el Minis- 
terio de Hacienda no se sirvió de ello y con el Texto Refundido se introduce la expresión «de carácter finalista» (art. 179).

Por último, el Tribunal de Cuentas tiene competencias indudables, encontrando un amplio apoyo legal a partir del artículo 136 de la Constitución y puesto que las Comunidades Autónomas, a excepción de Navarra, no pueden fiscalizar las cuentas y la actividad económica de las Corporaciones locales, circunstancia que alcanza, asimismo, a la Administración del Estado, sólo el Tribunal de Cuentas será el órgano competente (art. 2..$^{\circ}$ LOTC).

2. Tipos de control en función del momento en que se realiza:

Hasta 1981, las Corporaciones locales estaban sujetas en materia de presupuestos a un control preventivo del Ministerio de Hacienda, en materia de ejecución presupuestaria a un control gubernativo y en materia de rendición de cuentas a un control consultivo del Tribunal Central de Cuentas. En enero de 1981 van a desaparecer estos controles. El artículo 136 de la Constitución deslinda dos tipos de competencias del Tribunal de Cuentas: de un lado, la fiscalización de sus cuentas, y, de otro, la fiscalización de su gestión económica. El Tribunal de Cuentas debe abstenerse de cualquier tipo de control preventivo, limitándose al control final o consultivo.

3. Tipos de control en función de la finalidad perseguida:

El artículo 9. de la Ley Orgánica del Tribunal de Cuentas responde a los artículos 31.2 y 103 de la Constitución, en virtud de los cuales se somete a los principios de legalidad, eficiencia y economía, pero en un proceso global de control. El control de legalidad se orienta a conocer las infracciones legales, el control financiero se detiene en el tema de si las cuentas son o no representativas de la situación económica, el control de eficacia atiende a la consecución de los objetivos, el control económico a la utilización óptima de los recursos y el control de eficiencia a la utilización de los recursos en relación con los objetivos para su consecución con un coste mínimo.

4. Aspectos puntuales del control externo:

Se detuvo en dos aspectos por considerarlos especialmente relevantes:

a) La petición de documentos, que afecta no sólo a las cuentas sino que incide en el conjunto de facetas de la actividad económica de las Corporaciones locales y, a tal efecto, el artículo 43 
de la Ley Orgánica del Tribunal de Cuentas prevé medidas coactivas contra los morosos.

b) La fiscalización in situ, puesto que al Tribunal de Cuentas pueden llegar documentos de fiscalización, denuncia, etc., de muy variada procedencia.

\section{Segundo Ponente: D. Rafael Vicente Queralt}

Abordó la cuestión del control interno, planteándose, en primer lugar, la legislación aplicable. A este respecto, el Real Decreto legislativo 781/1986 establece todo un repertorio de disposiciones: las que dicten las Comunidades Autónomas (art. 5. de la Ley de Bases), la legislación de Régimen Local subsidiaria y las normas que dicten las propias Corporaciones locales. Con carácter subsidiario cabe la aplicación de la Ley General Tributaria, la Ley de Procedimiento Administrativo, Decreto de Medidas Urgentes, Ley y Reglamento de Contratos del Estado, Ley General Presupuestaria y Leyes de Presupuestos Generales del Estado.

A continuación se refirió a las diversas fases en que se manifiesta el control interno, distinguiendo entre una fase previa con examen previo de las actuaciones de la Administración, otra decisoria relativa al control financiero y una fase comprobatoria de los resultados, que constituye el control consuntivo.

Tras establecer los conceptos doctrinales de control y de control interno de legalidad, pasó a exponer la clasificación del control interno contemplada en las normas legales: función interventora (art. 16.2 LGP), contable (arts. 456.2 del Texto Refundido y 19 LGP), financiero (arts. 454 TR y 17.1 LGP) y control interno de eficacia (art. 17.2 LGP).

En cuanto a los órganos de control interno, el artículo 16.1 de la Ley General Presupuestaria se refiere a la autonomía de que goza la Intervención General en el ejercicio de esta función. Será, pues, la Intervención, en aplicación de lo dispuesto en el artículo 92.3 y disposición adicional séptima de la Ley de Bases y artículo 163 del Texto Refundido, la que realice las funciones de fiscalización propiamente dichas.

Se ha establecido la figura del reparo de legalidad, que debe formularse por escrito, no tiene efectos suspensivos y se sujeta a él toda la actividad económica y financiera. Se trata de un 
control de legalidad y su conocimiento corresponde al Ayuntamiento.

Se planteó la cuestión de que aunque en los Ayuntamientos de pequeños Municipios la Intervención desempeña las funciones propiamente dichas de intervención, de fiscalización y de gestión, la Ley sólo la atribuye las funciones de fiscalización interna, sin que pueda convertirse al mismo tiempo en gestor.

Otros órganos de control interno a los que hizo referencia son la Presidencia de la Corporación, la Comisión de Gobierno y el Pleno. En cuanto a la Comisión Especial de Cuentas, es especial en cuanto a su composición y en cuanto a sus competencias.

Como manifestación concreta de control interno señaló el control interno por muestreo, previsto en el artículo 455.3 del Texto Refundido que es objeto de la Circular 2/1984, de 20 de enero, de la Intervención General del Estado.

Por último, el artículo 26.3 de la Ley de Bases permite la interpretación de que las funciones de fiscalización y control se realicen por un órgano externo, pero, en cualquier caso, hay que afirmar la existencia de un vacío legal que ha de llenarse reglamentariamente.

Entre las conclusiones a extraer por el ponente cabe señalar las siguientes: Necesidad de un control interno integral, la conveniencia de utilizar técnicas más modernas, la utilización de mecanismos de control para la consecución de datos estadísticos y la necesidad de incrementar la imparcialidad y objetividad de los órganos de control interno.

Se presentó una comunicación relativa al control interno de los órganos dependientes de las Corporaciones locales, esto es, los órganos autónomos con personalidad jurídica y las empresas dependientes de las Entidades locales.

\section{EL CONTROL ECONOMICO-FINANCIERO DEL PRESUPUESTO: INDICADORES}

\section{Ponente: D. Gregorio Poveda Ponce}

A juicio del ponente, el endeudamiento no es una fuente financiera propia, sino una fuente derivada de ingresos y gastos. Partiendo de ello, los indicadores ¿para qué sirven? Sirven para 
hacer análisis comparativos dinámicos y estáticos y sirven también para investigar las desviaciones y encontrar los fallos. Respecto a cuáles son los indicadores a utilizar, son innumerables; pero señaló aquellos que consideraba más sugerentes.

En primer lugar, los indicadores de control presupuestario y de estructura financiera, referidos a los ingresos (Capítulos I al V), pero sin contemplar las contribuciones especiales por considerarlas ingresos finalistas que deberían figurar en el Capítulo VII del Presupuesto. Precisó que cuanto mayor era la homogeneidad mayor sería la desviación obtenida respecto a los indicadores standard.

Estos indicadores están referidos a un grupo homogéneo de Municipios y se comparan unos con otros. El primer indicador a utilizar serán los ingresos positivos por habitante; el segundo, los recursos financieros ordinarios por habitante, excepto los ingresos positivos, y un tercero vendrá constituido por la relación entre los dos conceptos anteriores. Hay que tener en cuenta que en los grandes Municipios el resto de los ingresos viene a reducirse al Fondo Nacional de Cooperación Municipal.

Deben compararse los indicadores de cada Municipio con los del grupo de Municipios que se estudia, procediendo a un análisis estático comparativo, referido a la relación porcentual entre los ingresos del Municipio y los del grupo, así como el peso de los ingresos impositivos respecto a los del grupo de Municipios.

En segundo lugar, pasó a referirse a los indicadores de estructura económica, eligiendo a efectos de su exposición, como indicador, la carga financiera, por lo que la técnica a emplear es igual a la seguida con anterioridad, pero los problemas son más grandes, ya que no se puede saber qué es la carga financiera. Hay dos tipos de carga financiera: directa e indirecta y existen dudas respecto del procedimiento para contabilizar las operaciones de Tesorería, que deben sacarse del Capítulo IX en el momento de liquidar el Presupuesto. De cualquier manera, la determinación de la carga financiera es importante para hallar el índice de endeudamiento.

Por último, hay otros indicadores, que son los de la estructura económico-financiera, que se obtienen relacionando los ingresos y los gastos. El índice a utilizar es el de cobertura de los gastos con los ingresos tributarios. Otro posible indicador sería el ahorro (habría que distinguir entre ahorro bruto y ahorro neto), entendido como ingreso de capital para financiar una serie de inversiones. 
Puede haber un presupuesto equilibrado con déficit si no se establece la comparación de los ingresos con gastos homogéneos, lo que desde un punto de vista económico puede ser diferente. Es necesario hallar la capacidad de financiación, que vendrá dada por la diferencia entre ingresos y gastos de capital, esta diferencia va a ser nuestra necesidad financiera y ese montante determina el nivel de endeudamiento a priori.

La facultad para endeudarse por esa cantidad es importante en orden a establecer las posibilidades de financiación de los costes derivados de la ejecución del Plan General de Ordenación Urbana.

Hay que determinar, asimismo, la carga financiera inicial potencial del Municipio, a la que hay que restar la carga financiera asumida en el pasado, que compararemos con la carga financiera derivada de las necesidades financieras. Si la carga financiera potencial es mayor que la derivada podemos endeudarnos por las necesidades de financiación e incluso más; en caso contrario, habría que buscar otros recursos o si no no se podrá satisfacerlas o habrá que hacerlo en años posteriores.

Respecto a los ratios de endeudamiento, indicó que la limitación del 25 por 100 no es técnicamente defendible, ya que el límite debe venir dado por la capacidad financiera o, en todo caso, correspondería al Banco de Crédito Local hacer estudios de viabilidad en la concesión de préstamos. Si hubiera que establecer un límite, debería ser el índice de ahorro que se genere. Otro aspecto a considerar sería la elasticidad del ingreso-gasto, ya que si se tiene capacidad financiera, pero la elasticidad es menor que 1 , hay que mejorarla porque en el futuro no habrá capacidad financiera

Existen otros indicadores de la capacidad fiscal del Municipio, tales como los valores catastrales, el parque de vehículos o la actividad económica, determinada por el cociente de dividir los derechos liquidados por el Ayuntamiento entre la renta, determinada preferentemente por la base imponible del Impuesto sobre la Renta de las Personas Físicas, sirviendo de ponderación la población, considerada como número de contribuyentes. 
PERSPECTIVAS DEL CONTROL FINANCIERO A LA LUZ DEL REAL DECRETO LEGISLATIVO 781/1986, DE 18 DE ABRIL, EN LAS SOCIEDADES MERCANTILES, ORGANISMOS AUTONOMOS Y ORGANOS DE GESTION SIN PERSONALIDAD JURIDICA DEPENDIENTES DE LAS ENTIDADES LOCALES

\section{Ponente: D. Francisco Bosch FerRer}

Abordó en su exposición cuatro aspectos:

1. El control en la Ley $7 / 1985$ y en el Real Decreto legislativo 781/1986:

La Ley de Bases es desconocedora del control o, al menos, parca en su regulación. El artículo 115 de esta norma se refiere al control de forma indirecta. Para ejercer el control debe depender de la existencia de algún obstáculo legal o financiero y la función fiscalizadora tiende a asegurar que los órganos directivos obren con arreglo a las leyes y conforme a lo más conveniente. En la Ley de Bases no existe el control financiero, ya que el artículo 114 está referido al control contable interno. El control contable es parte del control de la gestión financiera.

El Título VII del Real Decreto legislativo es de carácter básico, teniendo la Ley General Presupuestaria carácter supletorio, pero el contenido del control financiero se despacha en los artículos 454 y 455 del mismo, por lo que ¿la aplicación supletoria de la LGP puede entenderse también para el desarrollo reglamentario de la misma? A juicio del ponente hay que contestar afirmativamente, a tenor de lo dispuesto en el artículo 93.1, in fine, de la Ley General Presupuestaria.

2. Ambito de aplicación del control en las Corporaciones locales:

El concepto de control permite dos acepciones: amplia, referida al control jerárquico, y precisa, el existente en las finanzas públicas. De nuestro Ordenamiento Jurídico cabe extraer la existencia de control interno, externo y del plenario municipal. En la LGP se regulan los controles de legalidad, financiero, de eficacia y los procedimientos de auditoría. Respecto a las formas de control en cada uno de los órganos dependientes, el Texto Refundido no las establece, pero sí la Ley General Presupuestaria en sus artículos 99 y 100. 
3. El control de legalidad en las Corporaciones locales:

Según el coferenciante no es suficiente porque es necesario exigir eficacia económica en la gestión realizada, ya que si bien el control de legalidad puede ser deficiente, los órganos de gestión -en el supuesto de que existan- también pueden serlo.

Hay dos modalidades: el control contable y el control administrativo. El primero de ellos está dentro de lo que se entiende por contabilidad pública y viene a ser sinónimo de control presupuestario o financiero, si bien existen defensores de la existencia de un control específicamente presupuestario o control contable de justificación. En cuanto al control administrativo, regulado en el artículo 453 del Texto Refundido, se extiende a las competencias señaladas en este precepto.

La finalidad de estas técnicas de control es el adecuado manejo de los fondos públicos.

4. Control de carácter financiero:

Propugnó seguir el camino recorrido por la Intervención General del Estado, procurando no introducir elementos distorsionadores e intentando conseguir la coordinación de esta clase de control en todas las Administraciones Públicas.

El ámbito de aplicación del control financiero, conforme al artículo 454.1 del Texto Refundido debe entenderse remitido a la LGP, por lo que se puede practicar en órganos de gestión sin personalidad jurídica propia, en organismos autónomos (fundaciones públicas de servicios) y sociedades mercantiles.

Respecto a los órganos que pueden ejecutar el control financiero debe establecerse el criterio por similitud con el Estado, que se atribuyó a la Intervención General del Estado.

Las formas de ejecución del control financiero equivalente a las auditorías, abarcan lo financiero y lo legal y entre los requisitos para su ejercicio pueden enumerarse los siguientes: ubicación en la Intervención, creando una unidad especializada dotándola de medios humanos suficientes, elaboración en cada Corporación de un plan anual de auditorías, diciendo cuáles han de encomendarse a firmas privadas con garantías de control de calidad por parte de la respectiva Entidad local, organización de cursos de obtención de diplomas de auditoría por el Instituto de Estudios de Administración Local, etc., para elaborar normas de auditoría standard. 


\section{EL CONTROL DE GESTION DE LOS SERVICIOS PUBLICOS}

\section{Ponente: D. EsTEBAN MORRÁs ANDRÉS}

La información sobre la Administración Local es necesaria tanto para los Ayuntamientos como para los demás niveles de la Administración, puesto que las decisiones más importantes se toman fuera del ámbito local, ya que los dos instrumentos fundamentales de la autonomía local —potestad de legislar y recursos públicos- no están en manos de los Ayuntamientos.

Es preciso evaluar la gestión de los servicios públicos locales y hacer posible su medición, pero evaluar con objetividad es medir la efectividad, la calidad, los niveles de eficiencia y la satisfac. ción reportada a los usuarios en la relación coste/beneficio, con la prestación de los servicios públicos.

Evaluar la gestión es responsabilidad de los políticos y de los técnicos, correspondiendo a estos últimos establecer las condiciones internas de prestación de los servicios.

En las Administraciones provincial y autonómica pueden interesar varios aspectos; por ejemplo, en torno a los planes de inversión puede distinguirse entre un nivel deseable y otro real de prestación de los servicios, cuya diferencia supone el déficit dotacional, estableciendo la necesidad de dotar el nivel de eficiencia para poder determinar la aportación de cada Administración Local al Plan de Inversiones. Hay que tener en cuenta que, normalmente, los ámbitos institucionales no suelen coincidir con los ámbitos de gestión, por lo que en este sentido la colaboración interadministrativa ofrece amplias perspectivas.

Un problema señalado por el ponente es la falta de información de gestión, que está en una sifuación peor aún que la información contable que, al menos, está normalizada.

Se establece la necesidad de reformar aspectos que conciernen a la aprobación de planes de gestión y a la implantación del Presupuesto por Programas y el Plan General de Contabilidad Pública.

Expuso en relación con la implantación de cuadros de mando que constituyen un avance en el proceso expuesto, comportando una síntesis de información para controlar los servicios.

En cuanto a los servicios públicos locales que presta una Corporación en concreto, existen grandes diferencias, debiendo distinguirse entre servicios públicos obligatorios y voluntarios. Normal- 
mente se divide la actividad municipal en tres áreas: estructura interna de la Corporación, estructura de la ciudad y estructura que afecta a las personas como tales (servicios en general).

Teniendo en cuenta que el motor que mueve la actividad municipal es la inercia, es preciso establecer los objetivos de gestión de cada servicio público, concretar los productos outputs y los recursos inputs de cada servicio público, sin que puedan obviarse las dificultades que surgirán como consecuencia de la falta de una concepción empresarial. Para definir los outputs hay que situarse en una perspectiva finalista.

Se refirió a la necesidad de analizar las fases del servicio público, ya que su prestación es de tipo secuencial temporal y que sirve para concretar las actividades que se realizan para asignar las responsabilidades en el proceso productivo que tiene consecuencias organizativas. Por otra parte, hay que clarificar, seleccionar e intensificar la información, determinar los valores de referencia, etc.; en definitiva, la labor de medición de la gestión pública local hay que entenderla como un proceso gradual. 